\title{
Optimized Culture Conditions for Tissue Explants of Uterine Leiomyoma
}

\author{
A. FIEBITZ ${ }^{1}$, M. FRITSCH ${ }^{3}$, U. REICHELT $^{2}$, C. RUESTER $^{1}$, V. CHIANTERA ${ }^{1}$, \\ G. F. VERCELLINO ${ }^{1}$, A. DARWISH ${ }^{1}$, A. SCHNEIDER ${ }^{1}$, S. MECHSNER ${ }^{1}$ \\ ${ }^{1}$ Department of Gynaecology, Charité Hospital Campus Benjamin Franklin, Berlin, Germany \\ ${ }^{2}$ Department of Pathology, Charité Hospital Campus Benjamin Franklin, Berlin, Germany \\ ${ }^{3}$ Bayer Pharma AG Bayer HealthCare Pharmaceuticals, Berlin, Germany
}

\begin{abstract}
SUMMARY
Background: Uterine leiomyomas are the most common benign tumours in women, which arise from smooth muscle cells of the uterine myometrium and usually are multicentric. In spite of their frequency pathogenesis is widely unknown, mainly due to the absence of a suitable model system. We describe the systematic optimization of culturing leiomyoma tissue explants in an economical and effective ex vivo system.

Methods: Different concentrations of oxygen, different media, sera, hormones, and growth factor supplements were tested. Immunohistochemical stainings with antibodies against hormone receptors as well as specifying proliferation and apoptotic indices and real-time PCR were performed.

Results: Main parameters for culturing myoma tissue explants were tested for finding an optimal protocol. Standard medium D-MEM-F12 in combination with the use of horse serum in a reduced concentration of $1 \%$ turned out to be optimal for these tissue cultures as well as the addition of estradiol and epidermal growth factor EGF to media. Reduced oxygen content in the incubator air showed no positive effect.

Conclusions: For culturing tissue explants of uterine leiomyoma several conditions were optimized. The established tissue culture model allows examining the effects of known and potential therapeutic substances and the influence of immune competent cells in the process of tumour formation to find new targets for medical treatment. (Clin. Lab. 2012;58:1153-1164. DOI: 10.7754/Clin.Lab.2012.111117)
\end{abstract}

\section{KEY WORDS}

Uterine leiomyoma, ex vivo model, tissue culturing

\section{INTRODUCTION}

Uterine myomas are mostly multiple tumours arising as monoclonals from smooth muscle cells. The lifelong risk of getting myomas is about $70 \%$, and 10 to $25 \%$ of patients have symptoms such as pain, infertility, or bleeding problems, which seem to correlate with size, quantity and locations of the tumours [1].

Myomas are hormone dependant, but there are also other modulators of genesis and growth such as different tumour suppressors [2], locale cytokines and growth factors $[3,4]$, and, in addition, macrophages, T-cells, and mastocytes were found to be increased in myomas
[5]. Cell form and cytoskeleton are modified as well as amount, structure, and compounds of the extracellular matrix $[6,7]$.

Studies with microarrays or miRNA detected a number of genes differently expressed in myomas and myometrium, mostly associated with cell cycle regulation, differentiation, apoptosis, inflammation or the extracellular matrix. Other studies are based on animal models. Lead in this field is the so called "EKER rat", frequently developing myomas and other tumours due to a mutation in the TSC2 tumour suppressor gene. Besides the disadvantages such as high costs and effort, it should be kept in mind that the histology of the tissue is occasional sarcoma-like [8] and that not only reproductive biology but also pathways of human and rat are sometimes manifestly different. Thus, especially for detecting new tar-

Manuscript accepted February 14, 2012 
gets for medicament therapy of uterine myomas, animal models are limited. For example, the two hormonebased drugs Raloxifen and Tamoxifen showed very promising results in animal models $[9,10]$ but were very disappointing in clinical tests with premenstrual women $[11,12]$. Thus human model systems are not only desirable but necessary, and the lack of a suitable model is one of the main reasons for the nescience about the pathology of uterine myomas. Freshly extracted human tissue from hysterectomies is often used for analysing expression changes (see above) between myomas and myometrium, but this model is only of limited application for functional studies. Thus some scientists use cultivated cells from myomas; however to use them as a cell line they have to be immortalised by HPV-16 genes or telomerase-reverse-transcriptase $[13,14]$ due to scanty growth and early senescence under culture conditions $[15,16]$, which may change phenotype of myoma cells [17]. Another barrier to using cell cultures in myoma studies is the problem of fast cell dedifferentiation $[14,18,19]$. Within hours after beginning of culturing, m-RNA transcripts of ER and PR were decreased, independent of adding estrogens and/or progesterone. Gene expression between normal and tumour tissue in some cases is more similar than between tumour tissue and related culture [20]. Last but not least, the model system of cell culture could not consider cell interactions, autocrine and paracrine factors or the extracellular matrix (ECM), which is an important aspect in myoma (see above). The only useful cell line of uterine myoma is ELT3 from the EKER rat and thus from non-human origin. Even xenograft studies with laboratory animals $[8,21]$ could not completely fill the gap of the need of a broad based model without involvement of a non-human, non-menstruating organism. Thus there is a special need for an alternative model in the field of uterine leiomyoma. The cultivation of tissue explants offers such an alternative. This ex vivo model does not need any dissimilar organism, is low in cost and material effort, and takes all components of the tissue assembly including cell interactions and ECM components into account. This makes the cultivating of explants of this tumour tissue suitable for all fundamental questions as well as for studying new therapeutical applications. Here we present a suitable protocol for culturing tissue explants of uterine myoma with low cost and effort.

\section{MATERIALS AND METHODS}

\section{Tissue Culture}

The tissue for culturing came from myoma extracting surgeries, which took place at the Charité Campus Benjamin Franklin Hospital between October 2008 and February 2011, the decision of the ethics committee (EA4/117/09) is on hand. Directly after extraction, tissue is placed into cooled HANKS buffer (PAA). For cultivating, the material was cut into small, uniform slices using a Vibratom (Leica VT 1200S). This precise cutting machine with vibrating blade enables specified parameters providing comparable slices of $500 \mu \mathrm{m}$. Best results were achieved with an amplitude of $2.00 \mathrm{~mm}$ and frequency of $0.10 \mathrm{~mm} / \mathrm{s}$.

Embedding the tissue blocks in $4 \%$ agarose was tested, but was not beneficial because of the increased risk that the agarose block with the tissue separates from the holder. Beside this, the first aim is to reduce the time between myoma extraction and culturing in the incubitor as much as possible to get the best results in cell fitness.

Tissue slices were placed in 6-well plates for cell culture $\left(\mathrm{TPP}^{\circledR}\right)$ in combination with a metal grid set in each well ("grid-well"). Since the availability and composition of gas are important parameters for cultivation of other tissues [22,23], we compared standard 6-well plates $\left(\mathrm{TPP}^{\circledR}\right.$ ) for cell culture (with and without the use of a metal grid as holder for the tissue pieces in each well) with two other cell culture systems. One was the Lumox $^{\mathrm{TM}}$-cell culture system (in Vitro Systems), where the bottom is made of a special membrane und thus allows an increased gas exchange.

The other one was a "center well" culture dish (BD), with the additition of a "Nucleopore Track-Etch" membrane (Whatman ${ }^{\circledR}$ Schleicher \& Schuell). Tissue pieces were set on top of the membrane and thus had contact with the gas phase above and contact with the media below through the membrane. Rolling culture systems were not tested. They are mainly suitable for tissues with high requirement of oxygen, which is not the case for myoma. The Lumox ${ }^{\mathrm{TM}}$-cell culture system gave good results and is easy to handle; however, the much lower cost of the 6-well plates in combination with metal grids (named as "grid-well"), which were in same quality range, were chosen for further culturing. For economic use of the Lumox ${ }^{\mathrm{TM}}$ system, plates can be combined with flexi PERM discs (In Vitro) which are small plastic subdivisions for use in cell culture.

Culture media contained a final concentration of $1 \%$ antibiotic (penicillin/streptomycin, Biochrom), 1\% antimycoticum (amphotericin B, PPA), and 1\% L-Glutamin (Biochrom). To visualise the proliferation status of the tissue slices after culturing, BrdU (Bromodeoxyuridine, Sigma- Aldrich ${ }^{\circledR}$ ) was added to a final concentration of $10 \mu \mathrm{mol} / \mathrm{L}$. Sera and other supplements differ in some of the tests (see results), if not noted otherwise, horse serum (Biochrom) at a final concentration of $1 \%$ as well as estradiol E2 (Sigma-Aldrich ${ }^{\circledR}$ ) at a final concentration of $10^{-8} \mathrm{M}$ were added to D-MEM/F12 without phenol red $\left(\mathrm{Gibco}^{\circledR}\right)$ as standard medium. The addition of ITS (insulin transferrin selenium, Cellgro ${ }^{\circledR}$ Mediatech) showed no clear advantage in tests and was thus not used routinely (data not shown).

If not noted otherwise, culturing was done for 48 hours. Tissues were then fixed in $3.7 \%$ paraformaldehyde for embedding in paraffin and used in IHC or shock frozen in liquid nitrogen and stored at $-80^{\circ} \mathrm{C}$ for quantitative analysis via real-time PCR. As control for every experi- 
ment a cut slide without culturing was stored in paraformaldehyde or shock frozen.

\section{Immunhistochemical detection of selected markers}

To detect different markers in slices of cultured myoma tissue, they were fixed in $3.7 \%$ paraformaldehyde for a minimum of 24 hours directly after culturing and then embedded in paraffin. These tissue blocks were cut into $2 \mu \mathrm{m}$ slices and placed on glass slides. Before immunhistochemistry, slides were baked for 2 to 16 hours at $60^{\circ} \mathrm{C}$ and then deparaffinised in a descending alcohol series. Tissue pieces were inactivated in the manner appropriate for every staining. Antibodies were diluted in antibody diluent $\left(\mathrm{DAKO}^{\circledR}\right)$ and blocking was done with a $\mathrm{PBS} / 5 \%$ BSA solution. Biotin-based stainings were additionally blocked with Avidin and Biotin solutions $\left(\mathrm{DAKO}^{\circledR}\right)$; DAB-based stainings were blocked against endogen peroxidase (peroxidase blocking solution, DA $\mathrm{KO}^{\circledR}$ ).

In most cases, inactivation was done via heat in a steamer for 40 minutes followed by cooling in ice; the exceptions were BrdU and apoptosis detection (see below). To stain estrogen receptor (ER), "Target 9" (DA $\mathrm{KO}^{\circledR}$ ) was used as buffer during heat inactivation; all others were placed in citrate buffer in this step. The colouring system was Fuchsin Substrate-Chromogen (DA $\mathrm{KO}^{\circledR}$ ) and counterstaining was done with Mayers Hämalaun solution (Merck). After this, tissues were coated with Kaiser's glycerine gelatine (Merck) and covered with a glass coverslip.

Antibodies against the hormone receptors were monoclonal mouse anti-human ER alpha $\left(\mathrm{DAKO}^{\circledR}\right)$ and monoclonal mouse anti-human progesterone receptor PR $\left(\mathrm{DAKO}^{\circledR}\right)$. Alpha smooth muscle actin was detected by monoclonal mouse anti human alpha smooth muscle actin $\left(\mathrm{DAKO}^{\circledR}\right)$. Markers for the detection of the extracellular matrix (ECM) were monoclonal mouse anti dermatopontin (DPT) from Abnova and monoclonal mouse anti versican from Santa Cruz. Proliferation of the tissue slices were detected with monoclonal mouse anti-BrdU $\left(\mathrm{DAKO}^{\mathbb{R}}\right.$ ) and monoclonal mouse anti Ki-67 clone MIB-I $\left(\mathrm{DAKO}^{\circledR}\right)$. Secondary antibody was Biotin-SP conjugated Affini Pure Mouse Anti-Rabbit IgG (Jackson Immuno Research) and "Streptavidin-AP conjugated" from Roche.

Proliferation was carried out in two different ways. On the one hand, an antibody against BrdU added to the media in the beginning of tissue culturing (see above) was used, on the other hand, IHC was done with the Ki67 analogue MIB-I antibody. MIB-I staining was done as described for the detection of BrdU; deparaffinzied slices were demasked with $\mathrm{HCl}$ (10 minute incubation in $1 \mathrm{~N} \mathrm{HCl}$ on ice followed by 30 minute incubation in $2 \mathrm{~N} \mathrm{HCl}$ at $37^{\circ} \mathrm{C}$ ), neutralised with $0.1 \mathrm{M}$ borate buffer and water. The colouring system used here EnVision + System HRP (DAB) $\left(\mathrm{DAKO}^{\circledR}\right)$, and counterstaining was done with Mayers Hämalaun solution (Merck). After dehydration in an ascending alcohol series, samples were coated with Eukitt ${ }^{\circledR}$ quick-hardening mounting medium (Fluka BioChemika) and covered with a glass coverslip. For detection of apoptotic cells, the Apop Tag $^{\circledR}$ plus kit from Chemicon ${ }^{\circledR}$ was used. After descending alcohol series, tissue slices were demasked using the enzyme proteinkinase K (ExpressArt $\left.{ }^{\circledR}\right)$. Colouring system, counterstaining, and mounting of the slides were to the same as for the BrdU staining.

Evaluation and documentation for all stainings were done via light microscope (Zeiss, Axiophot) and a digital camera (Canon, Powershot G5).

\section{Analysis of mRNA via real-time PCR}

For quantitative analysis, the cultured tissues were shock frozen in liquid nitrogen and stored at $-80^{\circ} \mathrm{C}$ (see above). RNA extraction of myomas proved to be very difficult and therefore different protocols were tested. In conclusion, extraction via the trizol-chloroform-method turned out to be best; however, it was very important that tissues were kept frozen continuously (cooled with liquid nitrogen and dry ice) in the first step to shield RNA from degradation. In this step, tissue was crushed with a mortar until it was a fine powder, and then it was mixed with trizol. After this, in the trizol, the tissue was allowed to thaw. After separation with chloroform, precipitation, and washing steps, the quality of the RNA was controlled by nano-drop and used for c-DNA synthesis via SuperScript ${ }^{\circledR}$ II reverse transcriptase, random primers (Invitrogen ${ }^{\mathrm{TM}}$ ), and $\mathrm{RNasin}^{\circledR}$ ribonuclease inhibitors (Promega).

For real-time PCR, TaqMan ${ }^{\circledR}$ universal PCR master mix (Applied Biosystems) was used. Primers were PR Assay ID Hs01556702_m1*, ER Assay ID Hs001748 $60 \mathrm{~m}^{*}$, and GAPDH for normalisation (Assay ID Hs99999905_m1) from Applied Biosystems ${ }^{\text {TM }}$. Measurement was done using the software "Chromo 4 FourColour Real-Time Systems” (BioRad).

\section{Statistical Analysis}

All tests were done with a minimum of three biological replicates. Signals of the stainings were detected via light microscope. For proliferation and apoptotic indices, a 4-step scale was used $(0=$ no positive cell, $3=$ high number of positive cells), results of the proliferation stainings (BrdU and MIB-I) were merged. In all other cases, signals were classified in a percentage range. Results of the real time PRC were analysed using calculating delta $\mathrm{c}(\mathrm{t})$. Statistical analyses in all tests were made using GraphPad Prism 4 (GraphPad Software, USA). Statistical significances were determined accordingly by one-way ANOVA (Kruskal-Wallis test), Mann-Whitney, and paired t-test where $p<0.05$ was considered statistically significant. 


\section{RESULTS}

\section{Suitable media for culturing myoma tissue}

An important factor in finding optimal culture conditions is the choice of media. To find a suitable medium for culturing myoma tissue, standard media DMEM/F12 (Invitrogen ${ }^{\mathrm{TM}}$ ) and two special media for smooth muscle cells (MCDB-131 from c.c.pro $\mathrm{GMbH}$ and Smooth Muscle Cell Growth Medium from Promo Cell) were compared. All media were used in variants without phenol red since it has been suggested that this supplement could affect the growth of ER-dependent tissues [24]. Media were supplemented with antibiotics, antimycotics, L-glutamine, and serum as described above.

Comparison of the tested media regarding the proliferation index showed D-MEM/F12 to be almost similar to MCDB-131; smooth muscle cell growth media (SMC) showed bad results in all tests (Figure 1a). Similar results were found regarding the apoptotic index (1b), estrogen receptor, and progesterone receptor (data not shown). Since the results of D-MEM/F12 were significantly better compared to SMC and only minimal differences were seen between D-MEM/F12 and MCDB131 in all tests (no significances), the lower-priced media, D-MEM/F12, was chosen as the standard for all further experiments with myoma tissue cultures.

\section{Optimal serum for culturing myoma tissue}

The type of serum and its concentration could have a big influence on the culture quality. To determine the best composition of the nutrient solution for culturing uterine myoma, different sera and alternatives to serum as well as different concentrations of the sera were tested. Mostly we used common fetal calf serum (FCS), horse serum (HS), and Ultroser ${ }^{\mathbb{B}}-\mathrm{G}$ (CytoGen) as serum replacement, and compared these with tissue slices cultured in medium without any serum or serum replacement. Ultroser ${ }^{\circledR}-\mathrm{G}$ was used at a final concentration of $1 \%$, and FCS and HS were tested at concentrations of $5 \%$ and $1 \%$, respectively.

The highest proliferation index was found using FCS at a final concentration of $1 \%$, but differences were not significant (Figure 2a). In contrast, apoptosis was better than the other tested approaches using HS at a final concentration of $1 \%$ with or without Ultroser ${ }^{\circledR}-G$, but also here differences were not significant (Figure 2b). Detection of ER and PR in myoma tissues after culturing (immunhistochemistry as well as real time PCR of the hormone receptor's mRNA) showed no unique results for the different sera and no significant differences (data not shown).

All together, a final serum concentration of $1 \%$ seems to be better than $5 \%$. FCS seems to increase the proliferation index more than HS, but on the other hand, using HS lowered the apoptosis index compared to FCS. HS therefore was chosen as standard. serum replacement as Ultroser ${ }^{\circledR}-G$ showed no strong advantage (alone or in combination with HS), and because of higher costs it was not used for further tests.

\section{Addition of hormones to the medium}

Because of the known hormone dependence of uterine leiomyomata, we tested the addition of estrogens (estradiol E2) and progesterone (P) to the culture medium to show their effects on cultured slices of myoma tissue. Hormones were added together and individually at different concentrations from $10^{-6} \mathrm{M}$ to $10^{-10} \mathrm{M}$ and in comparison with tissue slices cultured in medium without addition of any external hormone.

\section{Addition of E2 alone}

Adding estradiol alone seemed to give the best results with a final concentration of $10^{-8} \mathrm{M}$ with respect to apoptosis, but most of the differences were not significant (Figure 3b). No significant differences with respect to the proliferation index were found (Figure 3a).

\section{Addition of $P$ alone}

Adding progesterone alone seemed to give the best proliferation and apoptotic indices using a final concentration of $10^{-6} \mathrm{M}$, but these differences were not significant (data not shown).

\section{Addition of E2 and P together}

When progesterone was combined with $10^{-8} \mathrm{M}$ estradiol (final concentration) as medium supplement, results were analogue to the addition of progesterone alone and showed no significant differences (data not shown). Neither estradiol nor progesterone in combination or individually have detectable positive effects on the hormone receptor proteins ER and PR (data not shown). All together, the addition of $10^{-8} \mathrm{M}$ estradiol seemed to be best in the test and showed a tendency toward a positive effect on culturing uterine myoma with regard to apoptosis. It showed an advantage versus the addition of progesterone and also when a combination of both hormones was used.

\section{Addition of EGF to the medium}

EGF is one of the growth factors which seem to have an important influence on the growth of myoma, thus we tested the effect of EGF on cultured tissue explants of this tumour. It was added to the culture medium to final concentrations from $10^{-7}$ to $10^{-10} \mathrm{M}$. These tests were compared with slices of tissue cultured in medium containing no external growth factor.

The best apoptotic index was found using a final concentration of $10^{-7} \mathrm{M}$ EGF (Figure 4a). The same concentration results in a higher amount of ER positive cells, but these differences were not significant (Figure 4b). Neither higher nor lower concentrations of EGF seem to have a clear influence on the amount of PR positive cells (data not shown). Proliferation was very low in all tests and showed no significant difference when EGF was added, no matter what concentration (data not 


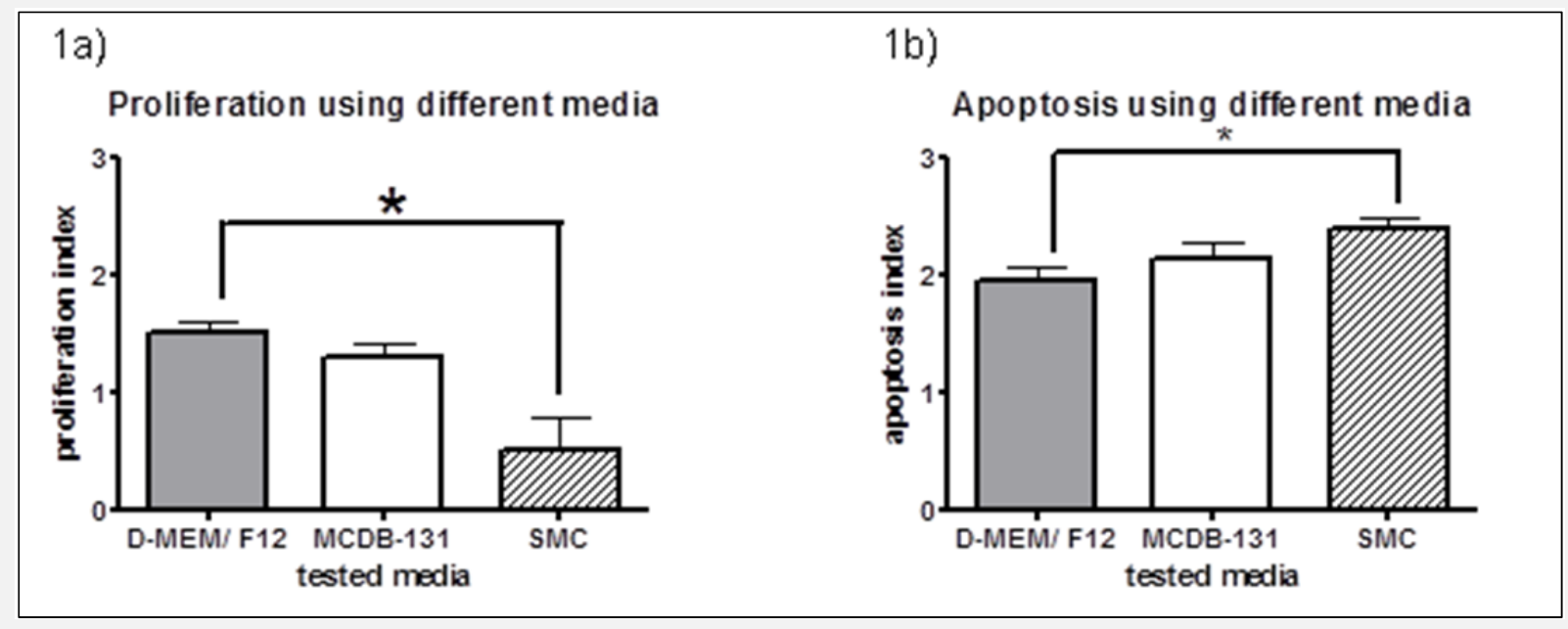

Figure 1. Comparison of different media (D-MEM/F-12, MCDB-131 and Smooth Muscle Cell Basal Medium (SMC)) for culturing uterine myoma tissue by analysis of proliferation index (a) and apoptotic index (b). Proliferation index using DMEM/F12 was significantly higher than the proliferation index when SMC was used; no significant differences were found between D-MEM/F12 and MCDB-131 or between MCDB-131 and SMC. Apoptosis was significantly higher with the use of SMC compared to D-MEM/F12. *p $<0.05$.

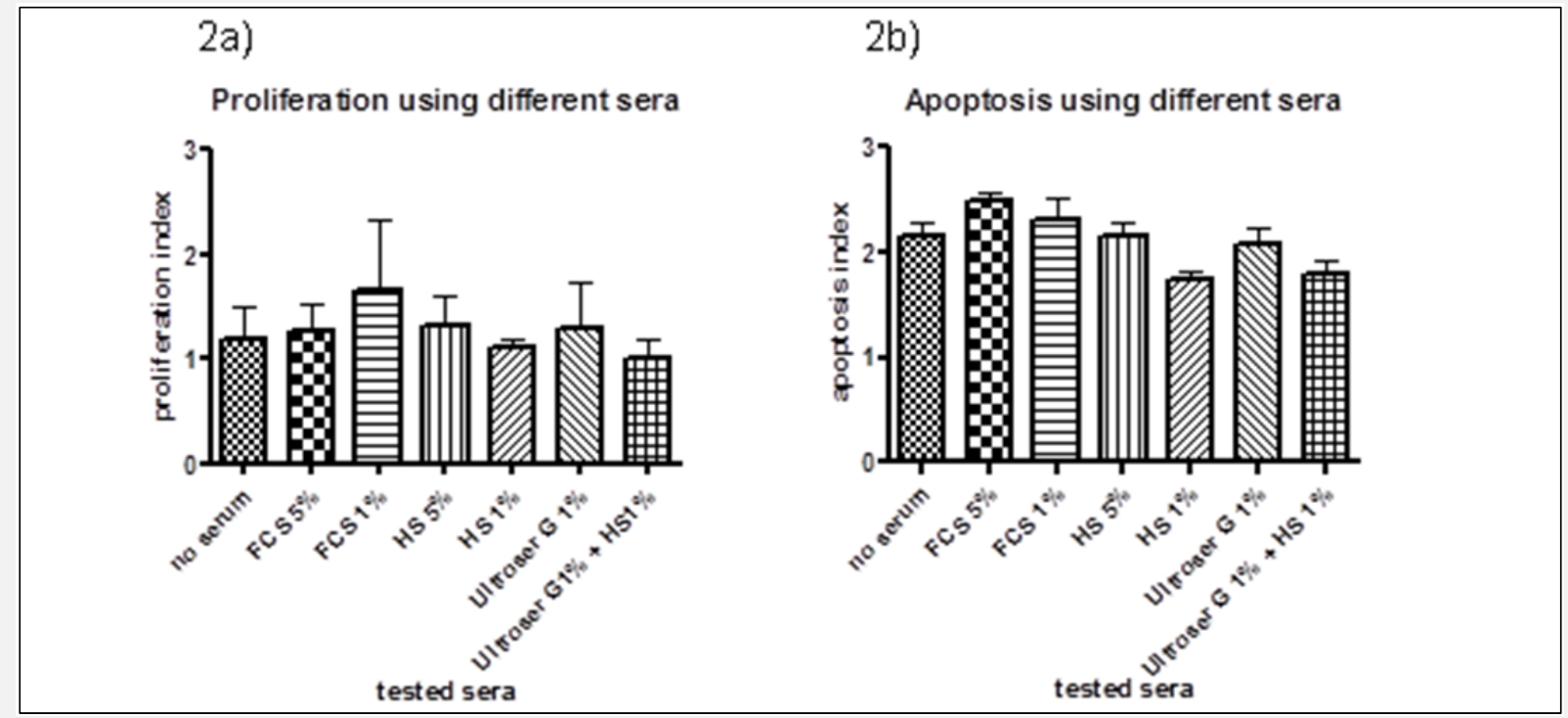

Figure 2. Comparison of different sera (fetal calf serum $=$ FCS, horse serum $=$ HS, and serum replacement Ultroser ${ }^{\circledR}$-G at different final concentrations in media for culturing uterine myoma tissue by analysis of the proliferation index (a) and apoptotic index (b). Differences between the proliferation indices using the different sera and concentrations were not significant. Apoptosis using $\mathrm{HS} 1 \%$ alone or in combination with Ultroser G $1 \%$ was lower than of all other tested serum combinations, but not significant. * $\mathbf{p}<\mathbf{0 . 0 5}$. 


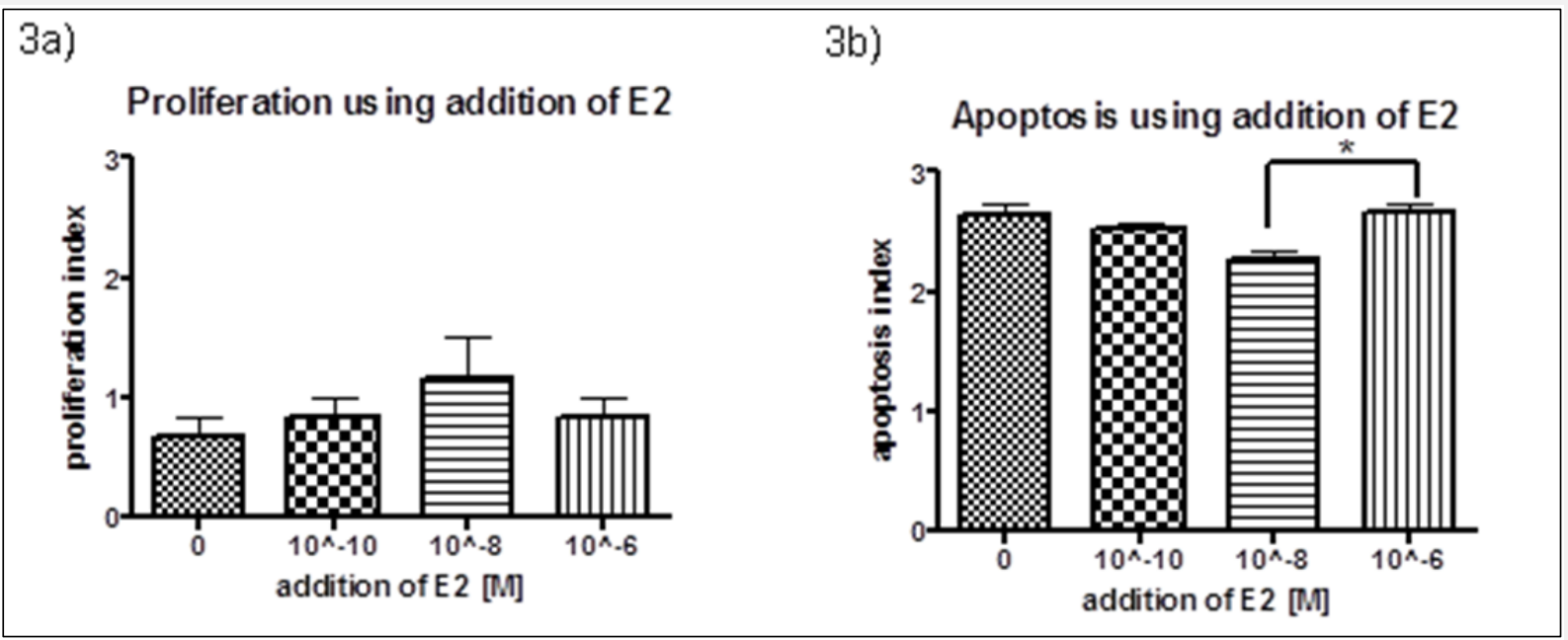

Figure 3. Addition of Estradiol E2 at different final concentrations from $10^{-6} \mathrm{M}$ to $10^{-10} \mathrm{M}$ in comparison to media without external hormones in cultured uterine myoma tissue analysed by proliferation index (a), and apoptotic index (b). Apoptosis was lower when E2 was added to culturing medium at a final concentration of $10^{-8} \mathrm{M}$, * $\mathrm{p}<0.05$.

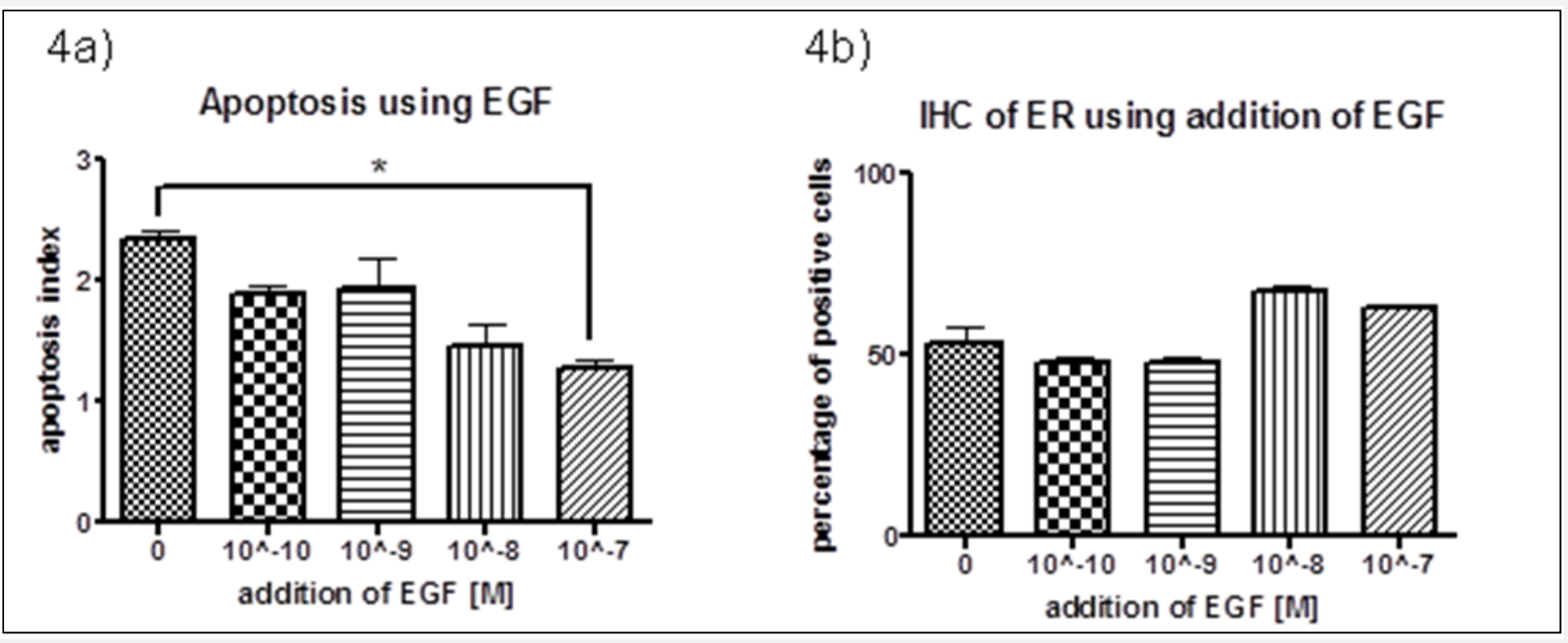

Figure 4. Addition of growth factor EGF at different final concentrations from $10^{-7}$ to $10^{-10} \mathrm{M}$ in comparison to media without external growth factors in cultured uterine myoma tissue analysed by apoptotic index (a) and IHC of ER (b). By using EGF at a final concentration of $10^{-7} \mathrm{M}$, the apoptotic index was significantly lower than without the addition of this growth factor; differences in IHC tests were not significant. * $p<0.05$. 


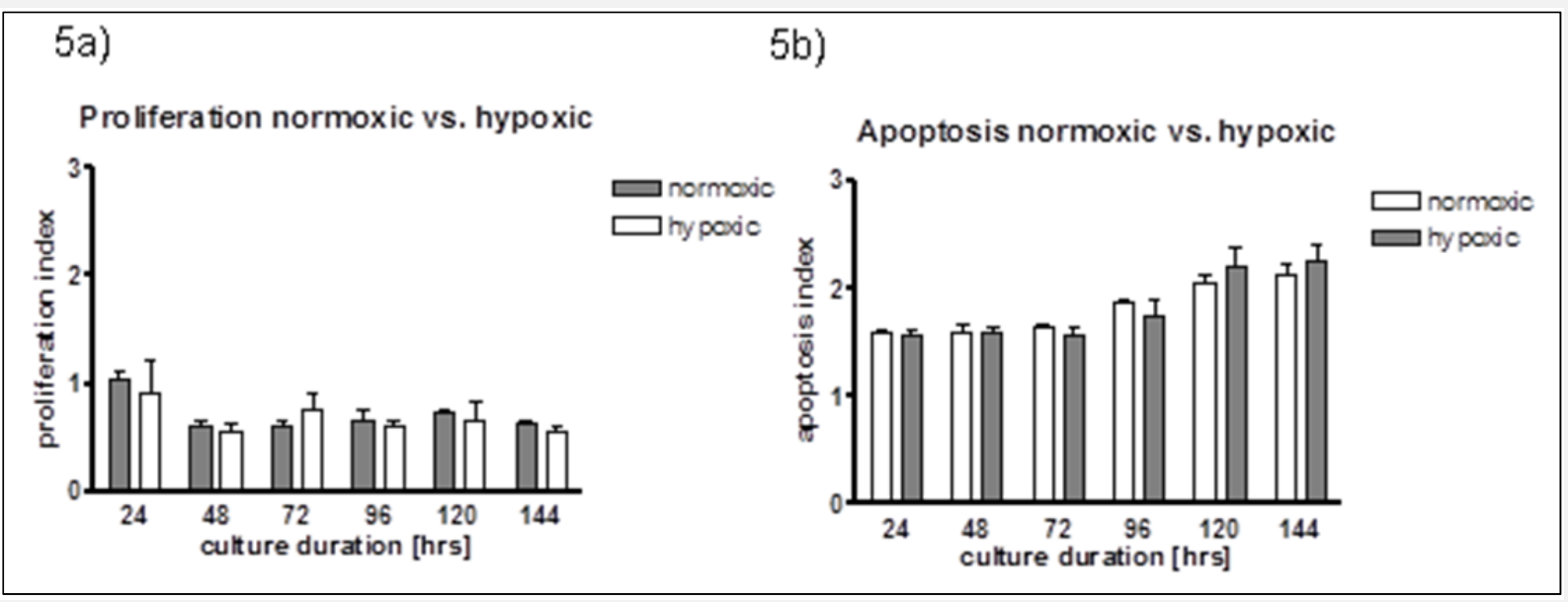

Figure 5. Myoma tissue explants cultured from 24 to 144 hours under normoxic vs. hypoxic conditions. Shown are the proliferation index (a) and the apoptotic index (b). No significant difference was found between the two gassing conditions, neither for the proliferation index nor for the apoptotic index, *p $<0.05$.

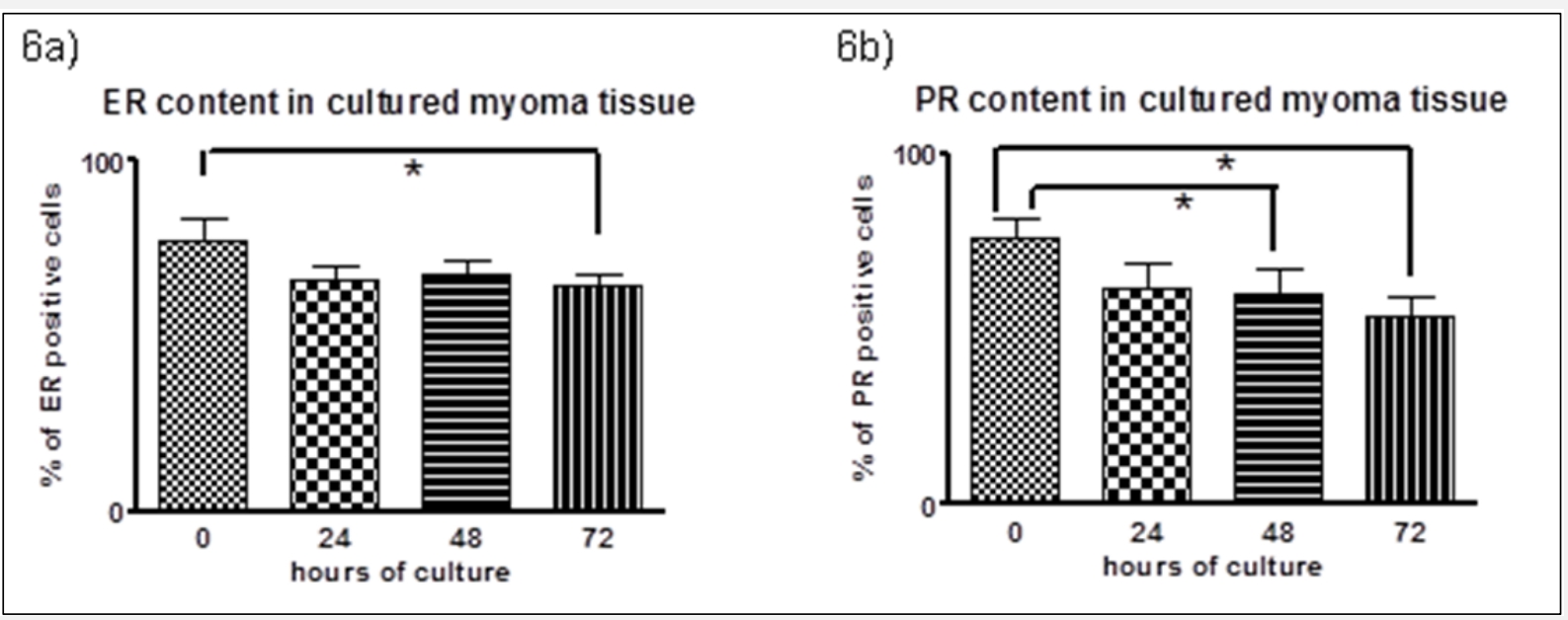

Figure 6. Presence of hormone receptors ER (a) and PR (b) in cultured uterine myoma tissue with regard to dif-ferent culture durations ( 0 hours of culture matches native tissue). The content of ER positive cells was signifi-cantly lower after 72 hours compared to native tissue. The content of PR positive cells was already significantly lower after 48 hours compared to native tissue. *p $<0.05$. 
shown). Taken together, the growth factor EGF seems to have a certain but low influence on cultured tissue explants of human uterine myoma, mostly on the apoptosis process.

\section{Examination of the influence of oxygen concentra- tion}

Another important parameter in cultivating myoma tissue could be the oxygen concentration in the incubator during culture, thus we compared two different concentrations in this study. We cultured tissue explants of uterine myoma in an incubator gassed either with standard normoxic gas $(20 \%$ oxygen, $5 \%$ carbon dioxide, $75 \%$ nitrogen) or with a special hypoxic gas ( $2 \%$ oxygen, $5 \%$ carbon dioxide, $93 \%$ nitrogen). Culturing was done for one to six days since it has been suggested that the oxygen effect only occurs after a certain time of culturing by increasing the life-span [25].

Culturing uterine myoma tissue explants under hypoxic conditions showed neither a higher proliferation index (Figure 5a) nor less apoptotic cells (Figure 5b), and thus no clear advantage over normoxic culture. Analyses of mRNA levels and contents of the hormone receptor proteins ER and PR in the tissues using immunohistochemistry analysis showed no advantage at any point of time tested for the culture of uterine myoma under hypoxic conditions compared with those cultured under normoxic conditions (data not shown). Based on these results, myoma tissues were cultured under normoxic conditions in all further tests.

\section{Hormone receptor content in relation to culture du- ration}

Because of the known rapid loss of hormone receptor protein in cultured myoma tissue, we tested the content of ER and PR in tissue cultured for 24, 48, and 72 hours as well as in native myoma using IHC (Figure 6). A decrease was already seen after 24 hours of culture, but these differences were not significant, neither with regard to ER (Figure 6a) nor to PR (Figure 6b). The first significant lower content of ER was found when tissue was cultured for 72 hours. PR content was only minimaly lower at 48 hours than at 24 hours, but not significantly different to native tissue.

\section{DISCUSSION}

Uterine leiomyomas are the most common benign tumours in women. Although they are the reason for numerous hysterectomies each year [26], the pathogenesis of leiomyomas is generally unknown, mainly due to the lack of a viable cell culture model. Uterine leiomyomas usually do not occur in typical laboratory animals like mouse or rat, and human systems are only available as primary cultures with all the problems already described. Even if cell based studies currently play an important part in myoma research, results should be reviewed critically prior to adopting for in vivo situations and/or for therapeutic considerations. Short-time culturing of tissue explants of leiomyomas provides an economical and effective alternative to cell culture and ethical controversy regarding animal and xenograft models. The problem is that culturing whole tissue slices is in general a very difficult method, last but not least because of their complex structures and all the different cell types with their special needs for culture conditions, which must be provided to keep original biological characteristics of the original tissue as long as possible. In particular, culturing uterine myoma tissue turned out to be a very special challenge not only because of its propensity to change the phenotype e.g. by loosing the hormone receptors in culture, but also because of its high morphological heterogeneity between different patients and even between different myomas of the same patient [27]. The size of the myoma [28] or other parameters not identified yet could be responsible for this. To establish tissue culturing as a dependable method even for sensitive myoma explants we here systematically optimised culturing conditions, and thus ensured that as much as possible of natural molecular biology in conjunction with characteristic qualities will be maintained during culturing time. As central parameters for culturing we tested different concentrations of oxygen, different media, sera, and supplements like hormones and EGF as important growth factors in uterine myoma pathogenesis. As a basic step toward finding the best way of culturing uterine myoma, we also tested different culture systems. With regard to cost and suitability, we found the best to be 6-well plates with a metal grid to hold tissue pieces, which were more or less equal to the much more expensive Lumox ${ }^{\mathrm{TM}}$ system. We also compared uncropped myoma with myoma cut by a vibratome. The cut explants were advantageous, and we carefully optimized the parameters for the vibratome cutting. In the beginning, there were some suggestions that embedding the tissue blocks in $4 \%$ agarose was useful to get equal slices of the very hard to cut myoma tissue. But after some tests it turned out that the agarose block increases the risk of damaging the tissue by separating from the metal holder of the vibratome. In addition, it took valuable time to place the tissue in the agarose. Since it is very important for cell health to be placed into culture media and incubator conditions as soon as possible, cutting in all further tests was done without agarose embedding.

Myoma tissue often turned out to be a very sensitive material, e.g. to extract RNA from this tissue needed testing of several protocols before we discovered the necessity of keeping the material frozen until pulverisation was completed and trizol was added. Even then the procedure is very sensitive and difficult, and the yield is oftent limited. For this reason, the amount of material is an important factor, thus protocols extracting RNA from paraffin embedded blocks seems to be a good alternative to the standard-trizol method. In this case, tissue pieces can be used for both IHC and RNA analysis 
at the same time. Pre-tests with two different protocols were promising.

\section{Suitable media for culturing myoma tissue}

An important factor for culturing cells or tissues is the choice of the media used. Besides standard media, there are numerous special media on the market. We compared MCDB-131 (c.c.pro GMbH), "smooth muscle cell basal medium" (SMC, PromoCell), both special media for cultivation of smooth muscle cells, and standard medium D-MEM/F12 (InvitrogenTM). All media were without phenol red because this may affect growth of ER-dependent tissues [24]. SMC showed the worst results in all parameters tested. Differences between DMEM/F12 and MCDB-131 were only small. Because of the much lower price per bottle, D-MEM/F12 was chosen as standard for culturing our myoma tissue explants.

\section{Optimal serum for culturing myoma tissue}

Similar to the media, the choice of serum as well as its concentration could strongly affect culture quality. Portier et al. showed medium with $2 \%$ horse serum or Ultroser $^{\mathbb{B}}-\mathrm{G}$ to cause muscular differentiation in myoblasts, whereas $10 \%$ fetal calf serum does not support differentiation [29]. Using media without any serum could be advantageous for the density of PR [30].

Myoma tissues were cultured in different concentrations in fetal calf serum (FCS), horse serum (HS), Ultroser ${ }^{\circledR}$ $\mathrm{G}$ (CytoGen), and without any serum or serum replacement. Differences were mainly seen in apoptosis, but even here they were not significant. It seems that horse serum at a final concentration of $1 \%$ is advantageous for culturing uterine myoma tissue. Lower concentrations of serum generally seem to have an advantage compared to higher concentrations and also to culturing myoma without any serum supplement. Ultroser ${ }^{\circledR}-G$ showed no clear advantage compared to the other substances tested. Due to the expense, it was not used after the pre-tests. All together horse serum at a final concentration of $1 \%$ was chosen because of its apoptosis index and its high relevance for culturing myoma tissues.

\section{Addition of hormones to the medium}

Myomas are hormone dependent tumours. Estrogens increase the growth rate, progesterone has both increasing and decreasing effects [27]. In this study, we tested the influence of these hormones on cultured slices of myoma tissue. Different tests with explants cultured in media without any hormone addition, in media with estradion (E2) and/or progesterone (P) in different concentrations showed that an addition of estradiol at a final concentration of $10^{-8} \mathrm{M}$ seemed to be advantageous over all other approaches. This fits with the doubleedged effect of progesterone shown in recent myoma research [31].

\section{Addition of EGF to the medium}

Growth factors seem to have an important influence on the growth of myoma [27]. One of them, EGF [32], is known to increase proliferation and inhibit apoptosis. We tested EGF in different amounts as a supplement to the medium for culturing uterine myoma. At a lower apoptotic index, when EGF is added at a concentration of $10^{-7} \mathrm{M}$, it seems that EGF has a positive influence on cultured tissue explants of human uterine myoma, especially on apoptosis of the cells in a light dose dependent manner. This corresponds with the study of Maruo et al., where they found EGF to be advantageous for myoma cell growing in culture because of the inhibition of apoptosis [33]. Estradiol, which inhibits the expression of $\mathrm{Bcl}-2$, is also responsible for decreasing apoptosis [34], but addition of this hormone was similar in all media for testing EGF effects and thus most likely not responsible for the differences found here. We could not confirm the positive effect of EGF on the proliferation rate of cultured human myoma cells [33] in our myoma tissue cultures. Proliferation was very low without significant differences in all tests.

It must also be kept in mind that myoma express EGF and EGF-R themselves, and that estradiol and progesterone increase these proteins [33,34]. Thus different myoma cells especially from different patients could have different endogenous EGF rates. But even if this effect has no influence on the results because of the precise and careful cutting and culturing treatment to guarantee equal conditions and because only samples from the same myoma source were compared, it cannot be absolutely excluded that growth factors are not excreted uniformly in the same tumour and thus may have an influence on our results.

\section{Examination of the influence of oxygen concentra- tion}

A very important question every scientist working with cultured cells or tissues has to ask regards the need and availability of oxygen for the cells. Normally, cell and tissue cultures in liquid media could be regarded as hypoxic, and it seems that only sufficient oxygen can keep the typical differentiation status of tissues [23]. Thus air exposure (AE) will be applied to many cell types, and Toda et al. found that cells in culture without AE turned necrotic and died much earlier [23]. But it is questionable whether this is also valid for uterine myoma. The uterus is a tissue with a comparably low need for oxygen, and leiomyomas are strongly hypoxic [35]. Aside from this, it was found that in some stem cell types hypoxia has the opposite effect. This means that it increases the growth [36,37]. In addition, hypoxia is a known key factor for the physiology of malignant growth and regulates several important genes in this process [38]. The physiological oxygen concentration of mesenchymal stem cells (MSC) is with 1 to $7 \%$ [39], much lower than in a normal cell incubator with about $20 \%$, which could stand for oxygenic stress for the cells. Thus, an increasing number of scientists cultivate their MSC under hypoxic conditions, which is advantageous mainly for long term culture $[25,37,38]$. Thus, the main effect seems to be not cell growth but expanded 
life-span [25]. Cells with stem cell type characteristics found in the myometrium [40] proliferated in vitro only under reduced oxygen concentration of $2 \%$. Therefore, it was worth testing the influence of lower oxygen concentration on the culture of myoma tissue explants. We compared hypoxic ( $2 \%$ oxygen) and normoxic (20\% oxygen) incubator conditions in a long term culture test. However, the lower oxygen concentration showed no advantage for the cultured tissue explants, not even in long term culture of 144 hours.

\section{Hormone receptor content in relation to culture du- ration}

As mentioned before, fast dedifferentiation of myoma cells in culture - especially the loss of hormone receptors - is a main problem in studying these tissues [14, 18,19]. After optimizing different parameters, we tested for the presence of hormone receptor proteins ER and PR in uterine myoma tissue cultured for 24,48 , and 72 hours and compared these data to native tissue. As expected, the amount of both receptors was lower in cultured pieces even after 24 hours compared to the content in native tissue. The first significant differences were found at 48 hours for PR and 72 hours for ER. Since there was only a minor difference of PR content between 24 and 48 hours and the clear decrease at 72 hours, culturing myoma for less than 48 hours using the culture conditions described here seems to be optimal for studying these tissues. This provides a satisfactory quality with regard to the protein status of ER and PR, very important parameters regarding the characteristics of this tissue. However, our data showed a visible, although not significant, decrease of the hormone receptors even after 24 hours of culturing, which might be the reason for the absent or rather low influence of additional hormone supplements in the medium regarding apoptosis, proliferation, and hormone receptor protein status (see above).

Taken together, the optimisation of the parameters tested for cultivating uterine myoma presented here promote culturing of these tissues as a promising alternative to the clearly more limited cell culturing and ethically controversial animal and xenograft approaches. This model, based on a much more natural biology than all others, has a wide spectrum for use, and results have a much higher probability to be transferable to human patients. This is necessary to be relevant for the allover aim of all myoma research: To find new therapeutic ways by enriching knowledge of this disease affecting so many women with pain, hyperhaemorrhage, and unwanted infertility. The protocol presented here for the culture of myoma tissue is a solid basis for using this approach for studying myoma tissue. However, it must be kept in mind that this also includes exploring the current problem of the immense heterogeneity of this tissue. Even myoma from the same patient can have very different proliferation rates, apparently independent of the tumour size [3]. This makes optimisation of culture conditions for these tissues extremely difficult. In the end, it is necessary to have a protocol which best suits all not only a special type of myoma, and this can only achieved as a compromise. To reach this goal, as many different myoma as possible were analysed and compared to find common denominators for culture conditions in the study presented here. One of the principal factors besides media, supplements, and incubator conditions and seems to be the minimisation of the time between extraction of the tissue from the patient and the time when this tissue is fed with medium under incubator conditions. In this very stressful space of time, cells are at a very high risk to start apoptotic processes, to loose their important biological characteristics like hormone receptors, or at the very least to lose their capability for mitotic activity.

Because of the high heterogeneity even this protocol presented here and very carefully optimised must be reassessed from time to time with other and more myoma sources. Nevertheless, for now it is a useful tool and a good alternative to all other models. Our next focus will be the use of this model to examine the effects of known and potential therapeutic substances (e.g. antiprogestins) on the cultured tissues and on the presence and influence of immune competent cells in the process of tumour formation to find new targets for medical treatment.

\section{Acknowledgement:}

This project was supported by Bayer Pharma AG Bayer HealthCare Pharmaceuticals, Berlin, Germany.

\section{Declaration of Interest:}

The authors are in no conflict of interest.

\section{References:}

1. Wei JJ, Soteropoulos P. MicroRNA: a new tool for biomedical risk assessment and target identification in human uterine leiomyomas. Seminars in Reproductive Medicine 2008;26(6):515-21.

2. Gao Z, Matsuo H, Nakago S, Kurachi O, Maruo T. Tumor suppressor protein content in human uterine leiomyomas and its down-regulation by 17 beta-estradiol. J Clin Endocrinol Metab 2002;87(8):3915-20

3. Dixon D, Flake GP, Moore AB, et al. Cell proliferation and apoptosis in human uterine leiomyomas and myometria. Virchows Arch 2002;441(1):53-62

4. Sozen I, Arici A. Interactions of cytokines, growth factors, and the extracellular matrix in the cellular biology of uterine leiomyomata. Fertil Steril 2002;78(1):1-12.

5. Luo $\mathrm{X}$, Chegini N. The expression and potential regulatory function of microRNAs in the pathogenesis of leiomyoma. Seminars in Reproductive Medicine 2008;26(6):500-14.

6. Wolanska M, Sobolewski K, Drozdzewicz M, Bankowski E. Extracellular matrix components in uterine leiomyoma and their alteration during the tumour growth. Mol Cell Biochem 1998; 189(1-2):145-52. 


\section{CULTURING UTERINE LEIOMYOMA}

7. Rogers R, Norian J, Malik M, et al. Mechanical homeostasis is altered in uterine leiomyoma. Am J Obstet Gynecol 2008;198(4): 474.e1-474.e11.

8. Hassan MH, Eyzaguirre E, Arafa HM, et al. A novel murine model for uterine leiomyoma using adenovirus-enhanced human fibroid explants in severe combined immune deficiency mice. Am J Obstet Gynecol 2008;199(2):156 e151-8.

9. Fuchs-Young R, Howe S, Hale L, Miles R, Walker C. Inhibition of estrogen-stimulated growth of uterine leiomyomas by selective estrogen receptor modulators. Mol Carcinog 1996;17(3):151-9.

10. Howe SR, Gottardis MM, Everitt JI, Walker C. Estrogen stimulation and tamoxifen inhibition of leiomyoma cell growth in vitro and in vivo. Endocrinology 1995;136(11):4996-5003.

11. Palomba S, Orio F Jr., Morelli M, et al. Raloxifene administration in women treated with gonadotropin-releasing hormone agonist for uterine leiomyomas: effects on bone metabolism. J Clin Endocrinol Metab 2002;87(10):4476-81.

12. Dilts PV Jr., Hopkins MP, Chang AE, Cody RL. Rapid growth of leiomyoma in patient receiving tamoxifen. Am J Obstet Gynecol 1992;166(1 Pt 1):167-8

13. Carney SA, Tahara H, Swartz CD, et al. Immortalization of human uterine leiomyoma and myometrial cell lines after induction of telomerase activity: molecular and phenotypic characteristics. Lab Invest 2002;82(6):719-28.

14. Malik M, Webb J, Catherino WH. Retinoic acid treatment of human leiomyoma cells transformed the cell phenotype to one strongly resembling myometrial cells. Clin Endocrinol (Oxf) 2008;69(3):462-70.

15. Varella-Garcia M, Chen L, Zheng X, Yu L, Dixon D. Karyotypic characteristics of human uterine leiomyoma and myometrial cell lines following telomerase induction. Cancer Genetics and Cytogenetics 2006;170(1):71-5.

16. Cramer SF, Robertson AL Jr., Ziats NP, Pearson OH. Growth potential of human uterine leiomyomas: some in vitro observations and their implications. Obstet Gynecol 1985;66(1):36-41.

17. Busnelli M, Rimoldi V, Vigano P, Persani L, Di Blasio AM, Chini B. Oxytocin-induced cell growth proliferation in human myometrial cells and leiomyomas. Fertil Steril 2010;94(5):186974.

18. Severino MF, Murray MJ, Brandon DD, Clinton GM, Burry KA, Novy MJ. Rapid loss of oestrogen and progesterone receptors in human leiomyoma and myometrial explant cultures. Molecular Human Reproduction 1996;2(11):823-8.

19. Zaitseva M, Vollenhoven BJ, Rogers PA. In vitro culture significantly alters gene expression profiles and reduces differences between myometrial and fibroid smooth muscle cells. Molecular Human Reproduction 2006;12(3):187-207.

20. Sandberg R, Ernberg I. Assessment of tumor characteristic gene expression in cell lines using a tissue similarity index (TSI). Proceedings of the National Academy of Sciences of the United States of America 2005;102(6):2052-7.

21. Greenberg LH, Slayden OD. Human endometriotic xenografts in immunodeficient RAG-2/gamma(c)KO mice. Am J Obstet Gynecol 2004;190(6):1788-95; discussion 1795-6.

22. Ootani A, Toda S, Fujimoto K, Sugihara H. An air-liquid interface promotes the differentiation of gastric surface mucous cells (GSM06) in culture. Biochem Biophys Res Commun 2000;271 (3):741-6.
23. Toda S, Watanabe K, Yokoi F, et al. A new organotypic culture of thyroid tissue maintains three-dimensional follicles with $\mathrm{C}$ cells for a long term. Biochem Biophys Res Commun 2002; 294(4):906-11.

24. Berthois Y, Katzenellenbogen JA, Katzenellenbogen BS. Phenol red in tissue culture media is a weak estrogen: implications concerning the study of estrogen-responsive cells in culture. Proc Natl Acad Sci U S A 1986;83(8):2496-500.

25. Fehrer C, Brunauer R, Laschober G, et al. Reduced oxygen tension attenuates differentiation capacity of human mesenchymal stem cells and prolongs their lifespan. Aging Cell 2007;6(6):74557.

26. Wilkens J, Chwalisz K, Han C, et al. Effects of the selective progesterone receptor modulator asoprisnil on uterine artery blood flow, ovarian activity, and clinical symptoms in patients with uterine leiomyomata scheduled for hysterectomy. J Clin Endocrinol Metab 2008;93(12):4664-71.

27. Maruo T, Ohara N, Wang J, Matsuo H. Sex steroidal regulation of uterine leiomyoma growth and apoptosis. Hum Reprod Update 2004;10(3):207-20.

28. Blake RE. Leiomyomata uteri: hormonal and molecular determinants of growth. J Natl Med Assoc 2007;99(10):1170-84.

29. Portier GL, Benders AG, Oosterhof A, Veerkamp JH, van Kuppevelt $\mathrm{TH}$. Differentiation markers of mouse $\mathrm{C} 2 \mathrm{C} 12$ and rat L6 myogenic cell lines and the effect of the differentiation medium. In Vitro Cell Dev Biol Anim 1999;35(4):219-27.

30. Yamada T, Nakago S, Kurachi O, et al. Progesterone down-regulates insulin-like growth factor-I expression in cultured human uterine leiomyoma cells. Hum Reprod 2004;19(4):815-21.

31. Marsh EE, Bulun SE. Steroid hormones and leiomyomas. Obstetrics and Gynecology Clinics of North America 2006;33(1):59-67.

32. Yeh J, Rein M, Nowak R. Presence of messenger ribonucleic acid for epidermal growth factor (EGF) and EGF receptor demonstrable in monolayer cell cultures of myometria and leiomyomata. Fertil Steril 1991;56(5):997-1000.

33. Maruo T, Matsuo H, Shimomura Y, et al. Effects of progesterone on growth factor expression in human uterine leiomyoma. Steroids $2003 ; 68(10-13): 817-24$.

34. Shimomura Y, Matsuo H, Samoto T, Maruo T. Up-regulation by progesterone of proliferating cell nuclear antigen and epiderma growth factor expression in human uterine leiomyoma. J Clin Endocrinol Metab 1998;83(6):2192-8

35. Mayer A, Hockel M, Wree A, Leo C, Horn LC, Vaupel P. Lack of hypoxic response in uterine leiomyomas despite severe tissue hypoxia. Cancer Res 2008;68(12):4719-26.

36. Morrison SJ, Csete M, Groves AK, Melega W, Wold B, Anderson DJ. Culture in reduced levels of oxygen promotes clonogenic sympathoadrenal differentiation by isolated neural crest stem cells. J Neurosci 2000;20(19):7370-6.

37. Grayson WL, Zhao F, Izadpanah R, Bunnell B, Ma T. Effects of hypoxia on human mesenchymal stem cell expansion and plasticity in 3D constructs. Journal of Cellular Physiology 2006;207(2): $331-9$.

38. Jin Y, Kato T, Furu M, et al. Mesenchymal stem cells cultured under hypoxia escape from senescence via down-regulation of p16 and extracellular signal regulated kinase. Biochemical and Biophysical Research Communications 2010;391(3):1471-1476. 
A. FIEBITZ et al.

39. Chow DC, Wenning LA, Miller WM, Papoutsakis ET. Modeling $\mathrm{pO}(2)$ distributions in the bone marrow hematopoietic compartment. II. Modified Kroghian models. Biophys J 2001;81(2):68596.

40. Ono M, Maruyama T, Masuda H, et al. Side population in human uterine myometrium displays phenotypic and functional characteristics of myometrial stem cells. Proc Natl Acad Sci USA 2007; 104(47):18700-5.

\section{Correspondence:}

PD Dr. Sylvia Mechsner

Departments of Gynaecology

Charité Hospital Campus Benjamin Franklin

Hindenburgdamm 30

12203 Berlin, Germany

Tel.: $\quad+49308445-2770$

Fax: $\quad+49308445-2937$

Email: sylvia.mechsner@charite.de 